\title{
Analysis of Pedestrian Gap Acceptance and Crossing Decision in Kuala Lumpur
}

\author{
Siti Naquiyah Mohamad Nor ${ }^{1}$, Basil David Daniel ${ }^{1,{ }^{*}}$, Rizati Hamidun ${ }^{2}$, Walid A Al Bargi ${ }^{1}$, \\ Munzilah Md Rohani ${ }^{1}$, Joewono Prasetijo ${ }^{3}$, Mohamad Yusri Aman ${ }^{1}$, and Kamarudin \\ $\mathrm{Ambak}^{3}$ \\ ${ }^{1}$ Faculty of Civil and Environmental Engineering, Universiti Tun Hussein Onn Malaysia (UTHM), \\ Johor, Malaysia \\ ${ }^{2}$ Malaysian Institute of Road Safety Research, (MIROS), Selangor, Malaysia \\ ${ }^{3}$ Smart Driving Research Centre (SDRC), UTHM, Johor, Malaysia
}

\begin{abstract}
Pedestrians are most vulnerable of all road users. This research aims to investigate and model pedestrian road crossing behaviour at crossing facilities. In particular, they have two aspects of pedestrians crossing behaviour are examined, namely the size of traffic gaps acceptance by pedestrians and the decision of pedestrians either to cross the road or not. A fields survey was carried out at six crossing facilities which from a zebra crossing at midblock. In this survey, the data were recorded in real traffic condition using video recorder. Determine the associations between characteristics of pedestrians, crossing facilities and vehicular traffic through on-site observations of pedestrian behaviour. This data will analysis using statistical analysis which is multiple regression and binary logit regression method. It is hope that through this research, the model of pedestrian gap acceptance and pedestrian crossing decision can be reached and what are the indicators that pedestrians look for when accepting gaps to cross the road.
\end{abstract}

\section{Introduction}

A pedestrian is defined as people who go on foot or who utilize assistive devices to facilitate them to walk. Walking is one of the most usual ways of moving for each person. Each type of mode transportation used also involves some by movement on foot. Walking can be categorized as one of the main modes of transport and it is healthier for human society [1]. Consequently, the pedestrian is one of the key elements in the system traffic, transportation arrangement, specially in urban traffic. The growth in pedestrian in Malaysia is parallel with the increment in population rapidly in Malaysia. In relation to this, the increase in the number of the pedestrian is also the reason of the increasing number of a traffic accident. A pedestrian was the most vulnerable when on the road. There has high traffic congestion in Malaysia, particularly in Kuala Lumpur. This situation can lead to conflicts between the movement of vehicles and pedestrians. This conflict sometimes can make accidents occurred on the pedestrian.

\footnotetext{
*Corresponding author: basil@uthm.edu.my
} 


\section{Literature review}

There are many different factors that affect the gap acceptance behaviour such as those relating to the site or location where the maneuvers take place, the conditions at the time of action and driver or vehicle involved. A gap in traffic is the space and time between vehicles and pedestrian. Some people might be can acceptable a gap in traffic, but some people might not be. Whether or not a gap is acceptable depends on the person's level of risk acceptance, how much the person trusts that the drivers will stop, and the person's perception of how long the gap is that perception may not be correct (the gap might be much longer or shorter than the person thinks it is).

The time spent waiting for safer gaps depend on whether the pedestrian is alone or in a group. Pedestrians tend to cross illegally (cross on red) if a member of the group initiates the illegal cross. In accepting gaps to cross, each pedestrian has a different perception on choosing the safest gap. Their physical characteristics affect their movement, i.e. walking speed. Taller pedestrians accept smaller gaps compared to shorter pedestrians due to them generally being able to walk faster [2]. The distance between the vehicles and the pedestrian have a significant effect on accepting safe gaps to cross [3]. Male pedestrians made the most inappropriate choices where they accepted smaller gaps to cross compared to their female counterparts discovered by [1]. Younger-old and older-old pedestrian group was also found to cross more slowly and accepts larger gaps than young pedestrian [4].

Previously study was found that the gap acceptance can find using some parameter such as with traffic condition and with the vehicular and pedestrian characteristic. Based on the gap acceptance theory researchers have developed mathematical models to represent the gap acceptance behavior of pedestrian with the help of pedestrian demographic characteristics such as gender and age [5], types of vehicle and waiting time [6], effect of rolling gap [7], effect of parked vehicles [8], non-compliant road crossing behavior at midblock locations [9], [10] and non-compliant road crossing behavior at signalized intersection [11].

\section{Research methods}

A field survey obtained the information about pedestrian crossing behavior. The selection of sites for pedestrian gap acceptance based on the area selected has the highest pedestrian count of 100 pedestrian/hour or more. The choices of sites also consist of the shopping complex, job center, public transport or education center. Six sites were chosen to observe pedestrian behavior in the area of Kuala Lumpur which is Lorong Gombak, Jalan Esfahan, Jalan Tun Perak, Jalan Pudu, Jalan Melaka and Jalan Merah Cagar. Manual counts were carried out to determine the volume of both pedestrians and vehicles, while a speed meter was used to measure vehicular speed. Video recording was recorded pedestrian who actually cross the road either using the crosswalk or not within 50 meters to know pedestrian flows and pedestrian behavior. The pedestrian that crosses a road at a distance more than 50 meters were not counted as samples for this study. Figure 1 shows an example of crossing facilities in Kuala Lumpur.

The process of street crossing can be excused by the utility maximization theory that pedestrians want to select the most satisfactory facilities and locations to cross the street. As a result, pedestrians make the utmost utility. It would be fair to assume that pedestrians' most satisfactory decisions are dependent on the location and the type of crossing facility. For instance, as shown in Figure 2, there are crossing facilities in the country. If a pedestrian's origin is in zone 4 and the destination is in zone 2, there are two potential routes to cross the street. The first path is to use the crosswalk and the second route is to use the overpass. Therefore, the existence of crossing facility may change pedestrians' crossing 
behavior and also induce a traffic violation because pedestrians cannot cross the street at the desired location.
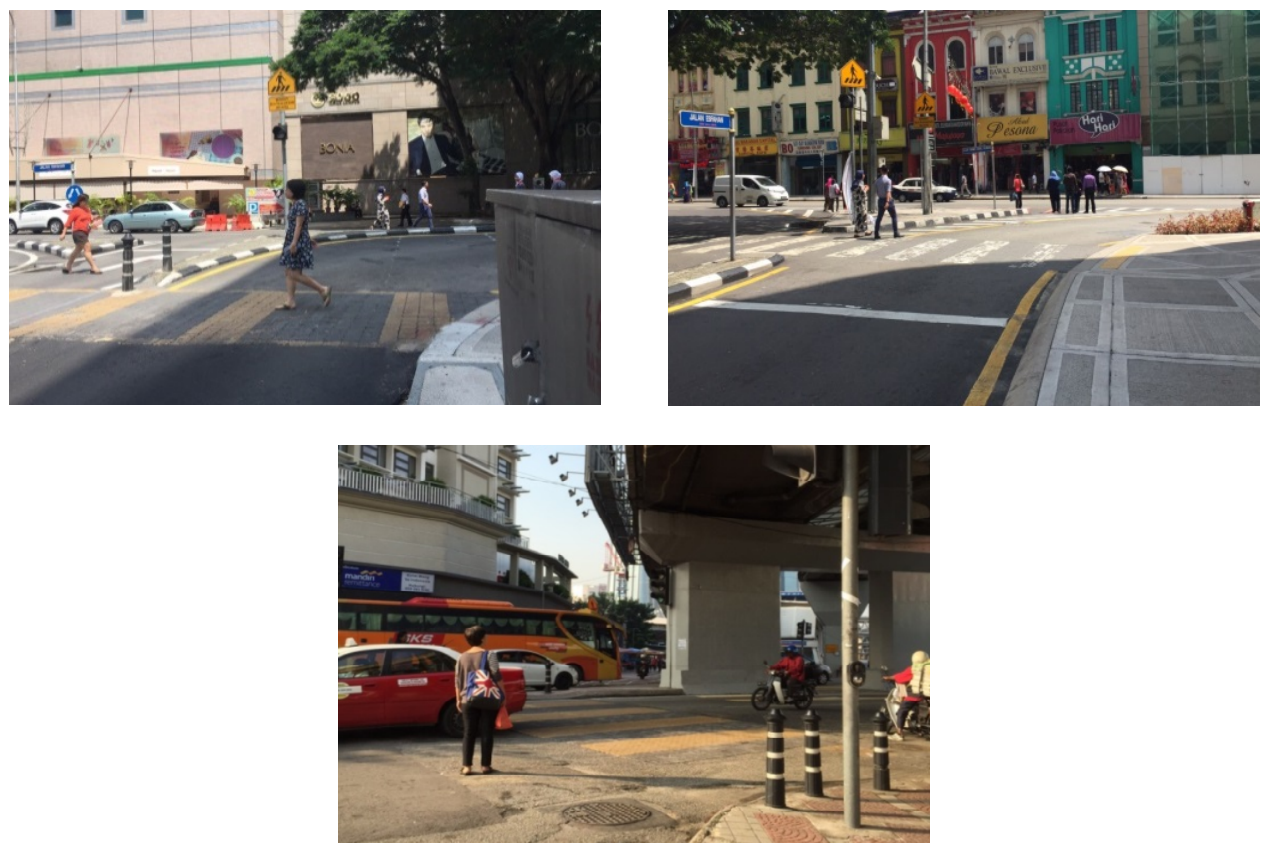

Fig. 1. Example crossing facilities in Kuala Lumpur

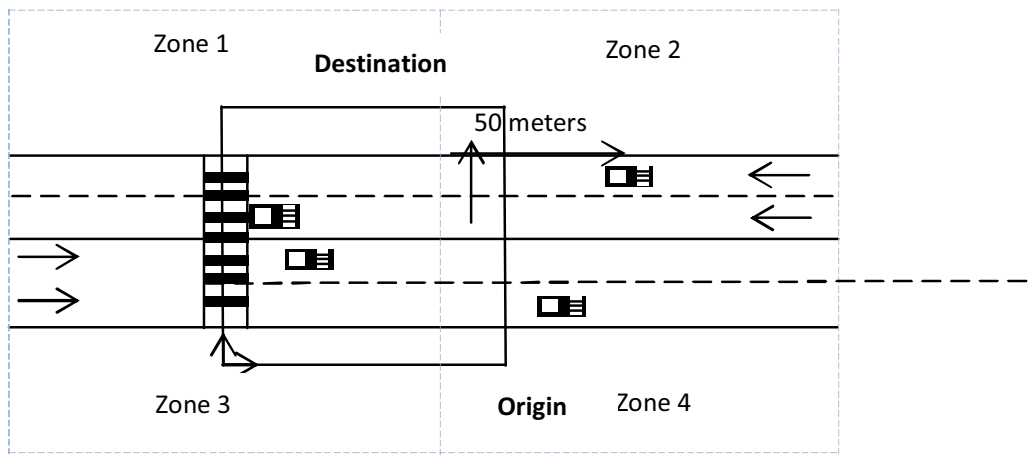

Fig. 2. Illustration of Crossing Route

\section{Model framework}

Analysis data is one of the processes to develop a model. All the data that have been collected has been analyzing for accuracy and suitability. Before beginning the analysis, there are several elements that should be recognized. This is very important to make sure the process will not affect for developing the model. A factor that must have to the identification of variables that to be included in the analysis are continuous variables and discrete variable. Data from video recording focused on the pedestrian crossing on the road either use crossing facilities or not use. The collected variables are shown in Table 1. 
Table 1. The Collected Variables

\begin{tabular}{|c|c|c|c|}
\hline Variable & $\begin{array}{c}\text { Type of } \\
\text { Variable }\end{array}$ & Unit or Code & Description \\
\hline Gap size & Continuous & Time in sec & $\begin{array}{l}\text { Time gap between two vehicles } \\
\text { with reference to crosswalk point }\end{array}$ \\
\hline Waiting time & Continuous & Time in sec & $\begin{array}{l}\text { Time spent at the curb or median } \\
\text { for suitable gap }\end{array}$ \\
\hline Vehicle speed & Continuous & $\mathrm{m} / \mathrm{s}$ & $\begin{array}{c}\text { Speed of the vehicle at crosswalk } \\
\text { area }\end{array}$ \\
\hline Traffic volume & Continuous & vehicle/hour & Volume of vehicle in crosswalk \\
\hline Pedestrian speed & Continuous & $\mathrm{m} / \mathrm{sec}$ & $\begin{array}{l}\text { The speed of the pedestrian while } \\
\text { crossing the road }\end{array}$ \\
\hline $\begin{array}{l}\text { Pedestrian } \\
\text { Volume }\end{array}$ & Continuous & pedestrian/hour & Volume of pedestrian in crosswalk \\
\hline Gender & Discrete & $\begin{array}{l}\text { 0: Women } \\
\text { 1: Man } \\
\text { 2: Both }\end{array}$ & Male or female \\
\hline Type of vehicle & Discrete & $\begin{array}{c}\text { 0: Motorcycle } \\
\text { 1: Car } \\
\text { 2: MPV } \\
\text { 3: Lorry and bus }\end{array}$ & Type of vehicle \\
\hline $\begin{array}{l}\text { Pedestrian } \\
\text { platoon }\end{array}$ & Discrete & $\begin{array}{c}\text { 0: Single } \\
\text { 1: Two } \\
\text { 2: More than two }\end{array}$ & Number of pedestrian in group \\
\hline Gap acceptance & Discrete & $\begin{array}{l}0: \text { Rejected } \\
1: \text { Accepted }\end{array}$ & $\begin{array}{c}\text { Whether pedestrian accepting gap } \\
\text { or rejecting }\end{array}$ \\
\hline
\end{tabular}

\subsection{Model pedestrian gap acceptance}

After several of the trials using SPSS software on different independent variables, the final model which has the best statistical results is developed. The gap acceptance was considered as the dependent variable and the remaining variables are considered as independent variables.

$$
\begin{gathered}
\text { Log-Gap }=34.663+0.529(W S)-0.271(W T)-1.477(G)-3.012(J)-0.252(V S) \\
+0.263(T V)-0.627(R W)
\end{gathered}
$$

Where; Log-Gap $=$ Logarithm of accepted gap, WS = Walking Speed, WT $=$ Waiting Time, $\mathrm{G}=$ Gender, $\mathrm{J}=$ Jaywalk, VS = Vehicle Speed, TV = Type of Vehicle, RW = Road Width. Based on the analysis has shown the $p$-value is less than $\alpha$ which is 0.05 . Therefore, the comparison shows that the null hypothesis $\left(\mathrm{H}_{0}\right)$ rejected. The value of $\mathrm{H}_{0}$ shows that there are an influence between gap acceptance and the factors. The descriptive statistics of multiple linear regression analysis test, $\mathrm{t}$-value and $\mathrm{p}$-value are summarized in Table 2. Reported t-value and p-value are statistical test values of each independent variable.

\subsection{Model pedestrian crossing decision}

The purpose of modeling pedestrian's crossing decision is to develop a linear function of the selected independent variable. In this study, there are 8 possible factors has been determined to influence pedestrian's crossing decisions which are gender, walking speed, waiting time, gap size, conformity psychology, jaywalking, vehicle speed, type of vehicle and road width. 
The model will provide the probability of a pedestrian either to accept or reject the street. Table 4.5 summarizes the descriptive statistic binary logit model.

Table 2. Summaries the descriptive

\begin{tabular}{|c|c|c|c|c|}
\hline \multicolumn{2}{|c|}{ Model } & Coefficients & $t$-value & $p$-value \\
\hline 1 & (Constant) & 34.663 & 22.141 & 0.000 \\
\hline & WS & .529 & 2.305 & 0.021 \\
\hline & WT & -.271 & -5.383 & 0.000 \\
\hline & G & -1.477 & -2.127 & 0.034 \\
\hline & $\mathrm{J}$ & -3.012 & -4.542 & 0.000 \\
\hline & VS & -.252 & -16.574 & 0.000 \\
\hline & TV & .263 & 3.785 & 0.000 \\
\hline & RW & -.627 & -3.391 & 0.001 \\
\hline
\end{tabular}

Table 3. Summaries the descriptive statistic Binary Logit Model

\begin{tabular}{|c|c|c|c|c|c|}
\hline & & B & S.E. & Sig. & $\operatorname{Exp}(B)$ \\
\hline \multirow[t]{8}{*}{ Step $1^{\mathrm{a}}$} & Walking Speed & -.059 & .051 & .245 & .943 \\
\hline & Waiting Time & .010 & .011 & .363 & 1.010 \\
\hline & Gap Size & -.012 & .006 & .028 & .988 \\
\hline & Jaywalk & -.084 & .145 & .561 & .919 \\
\hline & Vehicle Speed & -.033 & .040 & .001 & .876 \\
\hline & Type of vehicle & .020 & .019 & .286 & 1.021 \\
\hline & Road Width & .003 & .004 & .436 & 1.003 \\
\hline & Constant & 2.749 & .416 & .000 & 15.620 \\
\hline
\end{tabular}

Based on table 4.5 , the $p$-value is used to determine the variables that statistically fit the model. A significant value for each other factor that suitable for decision model must be less than 0.1 ( $p$-value $<0.1)$.

After the analysis, it is found out that gap size and vehicle speed are significant variables for the model whereby the significance value is less than 0.1 . The other factors are considered insignificant due to significant value more than 0.1 . Thus, the model is fitted by the method of maximum likelihood to the data as shown in Equation (2).

$$
z_{i}=2.749-0.012(G S)_{i}-0.033(V S)_{i}
$$

The probability for a pedestrian to cross the street based on gap size and vehicle speed may be explained by a binary logit regression model in the form as shown in Equation (3).

$$
P(U)=\frac{e^{(2.749-0.012(G S)-0.033(V S))}}{1+e^{(2.749-0.012(G S)-0.033(V S))}}
$$

\section{Analysis and discussion}

Most of the previous study gets a different gap size. The mean Malaysia pedestrian gap size at the crosswalk in second for man, women and both are 4.1, 5.4 and 4.9 respectively (Table 4). This value is higher than a study from [1] which for women is 4.876 second and man 3.422 second. It shows that women select larger gap than men. Difference for both 
categories. It can explain when a particular pedestrian is surrounded by several other pedestrians, he/she may feel protected by others and then may act more aggressively [10].

Table 4. The minimum accepted gap size for gender group

\begin{tabular}{|c|c|c|c|}
\hline \multirow{2}{*}{ Gender } & \multicolumn{3}{|c|}{ Gap Size (sec) } \\
\cline { 2 - 4 } & Minimum & Maximum & Mean \\
\hline Man & 3.5 & 5.5 & 4.1 \\
\hline Women & 4.6 & 8.0 & 5.4 \\
\hline Both & 4.1 & 7.4 & 4.9 \\
\hline
\end{tabular}

Fig. 3 shows the possibilities of a pedestrian's crossing decision according to the increasing speed of the vehicle and mean of gap size. According to figure 3, as speed increases, the possibility for a pedestrian to cross is decreased. When the vehicle speed is more $90 \mathrm{~km} / \mathrm{h}$ with the mean of traffic gap 3 seconds, pedestrian chooses not to cross.

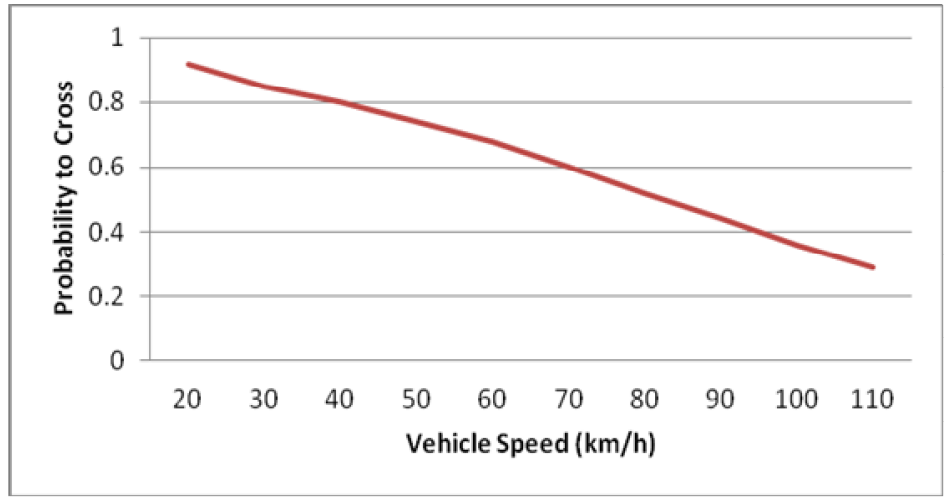

Fig. 3. Probability for a pedestrian crossing decision against vehicle speed

Fig. 4 shows the possibilities of pedestrian's crossing decision based on increasing gap size with the mean of vehicle speed. Based on the graph, it can be concluded that as gap size increases, the possibility of a pedestrian to cross is higher. When smaller gap size reduces, the possibility of a pedestrian to cross the road is lower.

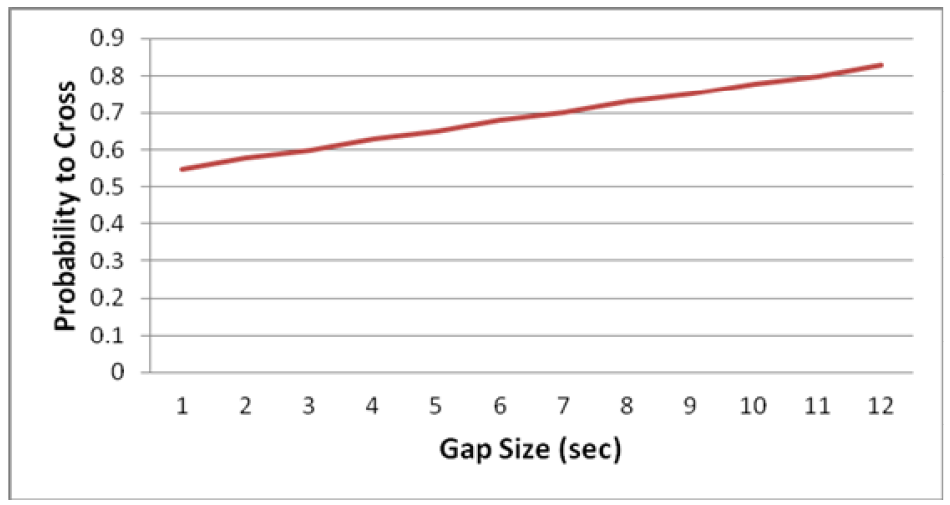

Fig. 4. Probability of a pedestrian's crossing decision against gap size 


\section{Conclusion}

This study analyzed the gap acceptance and crossing decision in Kuala Lumpur. Information was obtained through surveying and observation pedestrian at crossing facilities at 6 sites. The following conclusions are drawn based on the result:

i) A multiple regression model was developed in order to examine the variable that affected by the size of traffic gaps accepted by pedestrians. It was found that the gap size depends on walking speed, waiting time, gender, jaywalk, vehicle speed, type of vehicle and road width.

ii) A binary logit regression model was also developed in order to examine the variable that will affect to pedestrian when making the decision either to cross the street or not. The result showed that the decision depends on gap size and vehicle speed.

iii) The minimum gap size for man, women and both are 3.5, 4.6 and 4.1. It showed that man has a lower gap size because in the human nature there is an obvious difference between men and women at term of how aggressive they are.

iv) Probability to cross when vehicle speed was lower is higher, while the probability to cross the road when the gap size fewer is lower.

The findings of this survey show that pedestrian's gap accepted is significantly influenced not just by the vehicular traffic condition but also the road environment affect. Moreover, it was found that pedestrian crossing decisions are strongly connected with vehicle speed from the incoming vehicle and gap size because pedestrian`s choose not to cross if the vehicle speed is higher and the gap size were smaller.

The authors would like to acknowledge the financial support of the Ministry of Higher Education Malaysia under the Fundamental Research Grant Scheme (Project Reference No. FRGS/2/2014/TK07/UTHM/02/1/1485).

\section{References}

[1] B.R. Kadali and V. Perumal, Pedestrians' gap acceptance behavior at mid-block location, Int. J. of Engineering and Technology, 4, 158-161 (2012)

[2] B.H. Goh, K. Subramaniam, Y.T. Wai and A.A. Mohamed, Pedestrian crossing speed : the case of malaysia, Int. J. of Traffic and Transport Engineering, 2, 323-332 (2012)

[3] J.A. Oxley, E. Ihsen, B.N. Fildes, J.L. Charlton and R.H. Day, Crossing roads safely: An experimental study of age differences in gap selection by pedestrians, Accident Analysis and Prevention, 37, 962-971(2005)

[4] A. Dommes, V. Cavallo, J.B. Dubuisson, I. Tournier and F. Vienne, Crossing a twoway street: Comparison of young and old pedestrians, J. of Safety Research, 50, 27 34 (2014)

[5] A. Jain, A. Gupta and R. Rastogi, Pedestrian crossing behaviour analysis at intersections, Int. J. of Traffic and Transportation Engineering, 4, 103-116 (2014)

[6] D. Sun, S.V. Ukkusuri and R.F. Benekohal, Modeling of motorist-pedestrian interaction at uncontrolled mid-block crosswalks, Transportation Research Record, Urbana, 51, 61801(2002)

[7] M. Brewer, K. Fitzpatrick, J. Whitacre and D. Lord, Exploration of pedestrian gapacceptance behavior at selected locations. J. of the Transportation Research Board, 1982, 132-140 (2006)

[8] G. Yannis, E. Papadimitriou and A. Theofilatos, Pedestrian gap acceptance for midblock street crossing. Transportation Planning and Technology, 36, 450-462 (2013) 
[9] C. Cherry, B. Donlon, X. Yan, S.E. Moore and J. Xiong, Illegal mid-block pedestrian crossings in China: gap acceptance, conflict and crossing path analysis, Int. J. of Injury Control and Safety Promotion, 1-11 (2011)

[10] T. Wang, J. Wu, P. Zheng and M. McDonald, Study of pedestrians' gap acceptance behavior when they jaywalk outside crossing facilities, 13th Int. IEEE Conference, 1295-1300 (2010).

[11] J.M. King, D.W. Soole and A. Ghafourian, Illegal pedestrian crossing at signalized intersections: Incidence and relative risk, Accident Analysis and Prevention, 41, 485490 (2009) 